\title{
ST Depression in Preeclampsia Women Receiving Oxytocin during Cesarean Section: A Randomized Controlled Trial
}

\author{
Maria Jonsson $^{1 *}$, Ulf Hanson ${ }^{1}$, Christer Lidell ${ }^{2}$ and Solveig Nordén-Lindeberg ${ }^{1}$
}

${ }^{1}$ Department of Women's and Children's Health, Uppsala University, Uppsala, Sweden

${ }^{2}$ Department of Clinical Physiology, Uppsala University Hospital, Uppsala, Sweden

\begin{abstract}
Background: Electrocardiogram changes suggestive of myocardial ischemia, ST depressions, have been reported to be associated with oxytocin administration in healthy women undergoing cesarean section in regional anesthesia. We investigated whether there was a difference in the occurrence of ST depressions on electrocardiograms in preeclamptic women randomized to five or ten units of oxytocin during cesarean section with regional anesthesia.

Methods: Double-blind randomized controlled trial. Twenty-five women with preeclampsia delivered by cesarean section under spinal anesthesia were allocated to 5 or 10 units of oxytocin, given as an intravenous bolus. A Holter monitor was used to record electrocardiograms. Non-invasive blood pressure and heart rate were monitored. The main outcome measure was depression of the ST segment on electrocardiogram related to oxytocin bolus; the secondary outcomes were changes in mean arterial pressure and heart rate related to oxytocin bolus.
\end{abstract}

Results: ST depressions associated with oxytocin administration occurred in two women (8\%), one in each group. The decrease in mean arterial pressure from baseline to 2 minutes after the oxytocin bolus differed within groups, with $12 \mathrm{mmHg}$ in the five unit group and $16 \mathrm{mmHg}$ in the ten unit group $(p<0.01)$. The increases in mean heart rate from baseline to 2 minutes after the oxytocin bolus did not differ.

Conclusion: ST depressions on electrocardiograms were uncommon in patients with preeclampsia undergoing cesarean section in regional anesthesia, although the hemodynamic changes associated with an oxytocin bolus were substantial.

Keywords: Cesarean section; Electrocardiography; Heart; Hypotension; Ischemia; Oxytocin; Preeclampsia; Regional anesthesia

\section{Background}

Electrocardiogram changes, suggestive of myocardial ischemia, ST depression, have been observed in healthy women during elective cesarean section (CS) under regional anesthesia [1,2]. An association with oxytocin administration has been described, and oxytocin given as an intravenous bolus causes considerable dose-dependent hemodynamic changes such as marked hypotension and tachycardia [2-5]. Significantly more ST depressions following 10 versus 5 units of oxytocin have been reported in one study on healthy women during CS under spinal anesthesia [2].

The hemodynamic response to oxytocin in women with preeclampsia is of the same magnitude as in healthy women, but might be more difficult to predict compared with healthy women due to the heterogenicity in the clinical picture and antihypertensive treatment in preeclamptic women [6,7]. Cardiac dysfunction has been reported in women with severe preeclampsia and, after administration of an oxytocin bolus, a decrease in cardiac output has been demonstrated when preeclamptic women were delivered by CS under spinal anesthesia [7]. In light of these findings, women with preeclampsia could possibly be at greater risk for ST depressions related to oxytocin administration during cesarean section.

A slow intravenous bolus dose of 5 units of oxytocin following delivery of the infant is currently recommended to decrease blood loss in the third stage of labor during CS and, to our knowledge, there has been no other specific recommendation to women with preeclampsia [8].

In a double blind randomized study we aimed to find out if there was difference in the occurrence of ST depressions after injection of five or ten units of oxytocin in preeclamptic women delivered by CS under regional anesthesia. We compared the effect of the different doses on blood pressure and heart rate.

\section{Material and Methods}

The study was carried out at the Department of Obstetrics and Gynecology, University Hospital, Uppsala, Sweden, and was approved by the regional ethics committee. Informed written consent was obtained from all participants.

Preeclampsia was diagnosed if blood pressure was $\geq 140 / 90 \mathrm{~mm}$ $\mathrm{Hg}$ and if proteinuria of more than $1000 \mathrm{mg} /$ day persisted. Women $<18$ years of age, with body mass index $>35$, complications of the pregnancy other than preeclampsia, multiple births or with non-proficiency in the Swedish language were excluded.

Women were recruited to the study as in-patients once a decision on CS had been made. Randomization was computer-generated and participants were allocated into five or ten units oxytocin (Syntocinon ${ }^{\circledR}$; Novartis, Täby, Sweden). The oxytocin dose was prepared before

*Corresponding author: Maria Jonsson, Department of Women's and Children's Health, Uppsala University, SE-751 85 Uppsala, Sweden, Tel: +46/18/6110000(operator); Fax: +46/18/559775; E-mail: maria.jonsson@kbh.uu.se

Received August 27, 2012; Accepted September 17, 2012; Published Septembe 21,2012

Citation: Jonsson M, Hanson U, Lidell C, Nordén-Lindeberg S (2012) ST Depression in Preeclampsia Women Receiving Oxytocin during Cesarean Section: A Randomized Controlled Trial. J Hypertens 1:108. doi:10.4172/2167 1095.1000108

Copyright: (c) 2012 Jonsson M, et al. This is an open-access article distributed under the terms of the Creative Commons Attribution License, which permits unrestricted use, distribution, and reproduction in any medium, provided the original author and source are credited. 
surgery in a blinded syringe and diluted with $0.9 \%$ normal saline to a total volume of $10 \mathrm{~mL}$ by a pharmacist not involved in the study. Oxytocin was administered as an intravenous bolus over a period of 1 minute immediately after clamping of the umbilical cord. Additional doses of uterotonic drugs were available upon request by the surgeon.

The primary endpoint was depression of the ST segment of electrocardiogram (ECG) associated in time i.e. within 3 minutes) with the oxytocin bolus given immediately after delivery of the infant. The method used to find ST depressions on ECG during CS in the current study was identical to that used in our previous study on healthy women delivered by elective CS under regional anesthesia [2].

Continuous ambulatory ECG (Holter) monitoring (SEER/ MARS ${ }^{\circledR} 10109 ; \quad$ GE Medical systems, Buckinghamshire, United Kingdom) was used per-operatively with a chest modified V5 $\left(\mathrm{CM}_{5}\right)$ lead and a modified inferior lead. A significant ST segment change was defined as: $1 \mathrm{~mm}(0.1 \mathrm{mV})$ ST depression, starting $60 \mathrm{~ms}$ after the J-point and lasting for a minimum of 1 minute, horizontal or downward sloping. Recorded ECGs were analyzed for significant ST changes by a cardiologist blinded to patient data.

As secondary outcomes, mean arterial pressure (MAP) and heart rate (HR) were measured. Non-invasive blood pressure (systolic, diastolic, and MAP) and HR were monitored every 2 minutes, throughout surgery, using an automated blood pressure device $\left(\mathrm{GE}^{\circledR}\right.$ $\mathrm{DASH}^{\circledR} 4000$ Monitor; Soma Technology, Inc., USA).

Spinal anesthesia was commenced at lumbar interspace L2/L3 or L3/L4 using 27-gauge pencil point needles and in a sitting position. Hyperbaric bupivacain $5 \mathrm{mg} / \mathrm{mL}, 2-2.5 \mathrm{~mL}$ and fentanyl $50 \mu \mathrm{g} / \mathrm{mL}, 15$ $\mu \mathrm{g}$ were injected intrathecally. Mean arterial pressure was maintained within $15-20 \%$ of preoperative values and, hypotension associated with spinal anesthesia was treated with ephedrine $5 \mathrm{mg}$ or phenylephrine 50 $100 \mu \mathrm{g}$ bolus. Systolic blood pressure $<100 \mathrm{~mm} \mathrm{Hg}$ was not permitted. In case of a reflex decrease in heart rate occurring with phenylephrine, intravenous atropine $0.5 \mathrm{mg}$ was administered.

Oxygen was given continuously by nasal prongs at a rate of $2 \mathrm{~L} /$ min per-operatively. The surgical procedure was standardised using a Cohen incision and, immediate cord clamping, after which the placenta was removed by fundal massage and the uterus was thereafter exteriorised for repair. Left uterine displacement was maintained on the operating table until delivery of the infant.

\section{Statistics}

The incidence of ST depressions associated with intravenous oxytocin during CS in preeclamptic women is unknown. We decided to start a study with an early analysis in order to find out whether there was enough of a difference for the main outcome to justify going further. Due to the low frequency of ST depression after oxytocin bolus among women with preeclampsia that was shown in the early analysis, we could not justify or find it meaningful to continue.

The Statistical Package for Social Sciences (SPSS) for Windows, version 15.0, was used (SPSS, Inc., Chicago, IL, USA). To compare group distributions, the chi-squared test or Fisher's exact test was applied, while the Mann-Whitney U-test or $t$-test was used for continuous variables. A $\mathrm{p}$-value $<0.05$ was considered to indicate a significant difference.

\section{Results}

Participants were recruited from January 2006 to July 2008. During this period, 36 women gave their informed consent to participate, and 25 were subsequently randomized, 12 subjects to five units and 13 subjects to ten units of oxytocin. Reasons for not participating in the study or for not complying with the assigned group following randomization were failed spinal anesthesia resulting in general anesthesia, logistical problems in achieving ECGs and emergency cesarean sections during on-call hours.

Baseline demographics, clinical characteristics and indications for CS of trial groups did not differ between groups (Table 1). Mean gestational age at delivery was $33 \pm 4$ weeks in the 5 unit group vs. $33 \pm 5$ weeks in the 10 unit group. In total, premature delivery, $<37$ weeks, was observed in $18 / 25(72 \%)$ and $<34$ weeks in $12 / 25(48 \%)$. Sixty percent of women were treated with labetalol, seven $(58.3 \%)$ vs. eight $(61.5 \%)$ and nifedipine was used in three patients, two vs. one in the 5 and 10 unit groups, respectively (ns).

ST depression associated with oxytocin administration occurred in two women $(8 \%)$, one in each group. In figure 1 , mean MAP at baseline and after oxytocin administration is presented. There was no difference between groups in mean MAP prior to the oxytocin bolus. MAP (mean \pm SD) at baseline was $106 \pm 15$ vs. $107 \pm 13 \mathrm{mmHg}$ in the 5 and 10 unit groups. At 2 minutes after the oxytocin bolus, there was a significant decrease in MAP within groups, with $12 \mathrm{mmHg}$ in the five unit group and $16 \mathrm{mmHg}$ in the ten unit group ( $\mathrm{p}<0.01$ ), but no difference was seen between groups.

In figure 2, mean $\mathrm{HR}$ at baseline and after oxytocin administration is illustrated. There was no difference in mean HR at baseline, $89 \pm$

\begin{tabular}{|l|l|l|}
\hline & $\begin{array}{l}\mathbf{5} \text { units oxytocin } \\
\mathbf{n = 1 2}\end{array}$ & $\begin{array}{l}\mathbf{1 0} \text { units oxytocin } \\
\mathbf{n = 1 3}\end{array}$ \\
\hline Nulliparous & $8(66.7)$ & $9(69.2)$ \\
\hline Gestational age, weeks & $33 \pm 4$ & $33 \pm 5$ \\
\hline Maternal age, years & $32 \pm 7$ & $31 \pm 7$ \\
\hline Smoking during pregnancy & 0 & 0 \\
\hline Body mass index, (BMI) $\mathrm{kg} / \mathrm{m}^{2}$ & $28.2 \pm 4.8$ & $26.4 \pm 4.9$ \\
\hline Indication for cesarean section: & & \\
\hline Preeclampsia & $10(83.3)$ & $7(53.8)$ \\
\hline Breech & 0 & 2 \\
\hline Previous cesarean section & 0 & 1 \\
\hline Psychosocial & 1 & 2 \\
\hline Failed induction & 1 & 1 \\
\hline
\end{tabular}

Values are given as means \pm standard deviation (SD) or $\mathrm{n}(\%)$

Table 1: Demographic and baseline data.

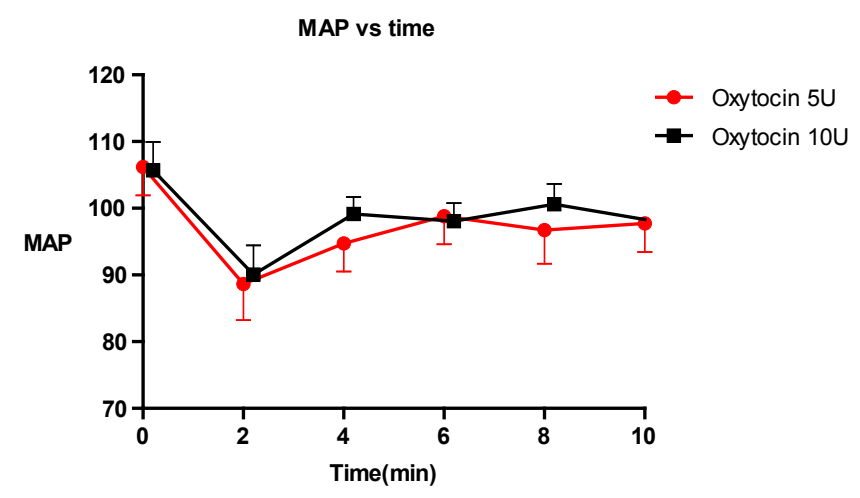

Figure 1: Mean arterial pressure (MAP), time (minutes) from oxytocin administration. The data points are mean \pm standard deviation. 
7 vs. $86 \pm 14$ beats per minute (bpm) in the five and ten unit groups respectively. Increase in mean HR from baseline to 2 minutes did not differ between groups. The average increase in HR was $10 \mathrm{bpm}$ in the five unit group and $16 \mathrm{bpm}$ in the ten unit group.

Time from the induction of anesthesia to delivery did not differ: 23 \pm 7.3 minutes (mean \pm standard deviation (SD) vs. $23 \pm 8.8$ minutes in the 5 and 10 unit groups, respectively (ns). There were no differences in type, number of doses or amount of vasopressors given between groups, in median $7.5 \mathrm{mg}$ Ephedrine and $0.1 \mathrm{mg}$ Phenylephrine was administered in the five unit group compared with $10 \mathrm{mg}$ and $0.1 \mathrm{mg}$ in the ten unit group. Atropine was given in two women in the five unit group and in one woman in the ten unit group. No additional oxytocin was requested. One of the patients receiving five units was given misoprostol rectally.

\section{Discussion}

The occurrence of ST depressions on ECGs after the oxytocin bolus dose was infrequent in women with preeclampsia undergoing CS under spinal anesthesia though the oxytocin bolus was followed by transient hypotension and tachycardia. Since the mean MAP reached the lowest level of about $90 \mathrm{mmHg}$ after the oxytocin bolus, we speculate that the perfusion of coronary arteries was sustained despite a decrease in MAP $[9,10]$. This could possibly explain why the occurrence of ST depressions was less frequent in preeclamptic women compared with what has been described in healthy women. Our finding indicates that the risk of ST depression seems to be low in these women who otherwise are at high risk for cardiopulmonary morbidity during the peripartum period [11].

The value of routine oxytocics in the third stage of cesarean delivery to prevent excessive bleeding has been well established $[12,13]$. Routine oxytocics are also recommended in women with cardiac disease as well as in women with preeclampsia [14,15] Women with preeclampsia have an increased risk of cardiopulmonary morbidity, and since oxytocin administered during CS in spinal anesthesia causes significant hemodynamic changes in women with preeclampsia, it has been suggested that oxytocin should be administered with caution [6] Small doses of oxytocin administered by slow intravenous infusion are currently recommended during CS under regional anesthesia in women with severe preeclampsia [6,7].

In a study on 18 women with severe preeclampsia by Langesaeter et al. [4,7], the hemodynamic response to a 5 unit intravenous bolus of oxytocin after delivery by cesarean section under spinal anesthesia was studied. In keeping with the results of our study, all patients showed a

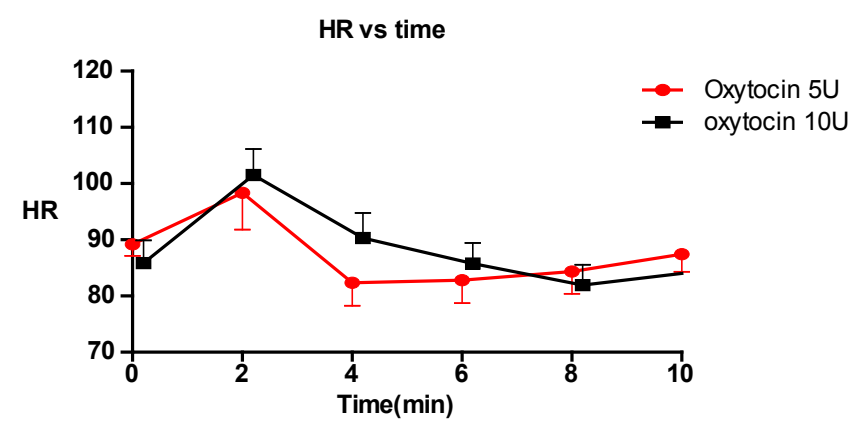

Figure 2: Heart rate (HR), time (minutes) from oxytocin administration. The data points are mean + standard deviation. decrease in systolic arterial pressure and an increase in heart rate [7] interestingly, five out of the eighteen women had a decrease in cardiac output due to a decrease in stroke volume. In a study by Dyer et al. [6], using a 2.5 unit bolus of oxytocin, no decrease in cardiac output following oxytocin was reported, indicating that the effect may be dosedependent [6]. Cardiac dysfunction with decreased cardiac output would also have an effect on the supply of coronary arteries and lead to a shortage of oxygen in the cardiac muscle. However, the results of our study in which 5 or 10 units of oxytocin were administered indicate that women with preeclampsia may not be at increased risk for cardiac strain reflected by ST depressions after administration of oxytocin during CS under regional anesthesia. The oxytocin receptor mediated cardiac and vascular effects may be different in the preeclamptic woman compared with in the healthy woman but, there are to our knowledge, no in vitro or in vivo studies to support that oxytocin receptors in subjects with preeclampsia have a different response to oxytocin.

Preeclamptic women undergoing CS under spinal anesthesia have a decreased incidence of spinal anesthesia-induced hypotension requiring vasopressor drug treatment as compared with healthy women, which is in keeping with the results in the present study $[6,16]$. The higher vascular tone that characterizes these patients and the increased sensitivity to press or drugs have been discussed as possible explanations for these findings $[16,17]$.

A limitation of our study was the non-invasive monitoring of patients. Blood pressure and HR were measured at 2-minute intervals and the short-acting effect of oxytocin on hemodynamic variables may have been underestimated. Further, we did not restrict our inclusion criteria to women with severe preeclampsia, although the majority of women had premature delivery indicating severity. We acknowledge that the conclusions of the study are limited by the small sample size of the study groups, and that there is a risk of type II error. To conduct randomized trials in this population is difficult, and due to the low frequency of ST depressions, we did not find it meaningful to continue, since it would require a large number of subjects, heavy expenses and we also considered the difficulties in the recruitment of women.

In conclusion, ECG changes suggestive of myocardial ischemia were uncommon in women with preeclampsia undergoing CS under spinal anesthesia. Possibly, the higher vascular tone in women with preeclampsia maintains adequate coronary blood flow despite the decrease in mean arterial pressure. The incidence and risk of ST depressions associated with an oxytocin bolus may be less in preeclamptic women than in healthy women undergoing CS under spinal anesthesia.

\section{Competing Interests}

The authors report no conflict of interest.

\section{Contribution to Authorship}

Maria Jonsson carried the main responsibility for conducting the study acquiring the data and drafting the manuscript. All authors collaborated in the conceptualization and the design of this study, revised the manuscript and approved the final manuscript.

\section{Details of Ethics Approval}

This study was approved by the Research Ethics Committee at Uppsala University in February 2005 (D-number 2004: M-474).

\section{Funding}

The study was financially supported by The Erik, Karin and Gösta Selander Foundation and the General Maternity Hospital Foundation. 
Citation: Jonsson M, Hanson U, Lidell C, Nordén-Lindeberg S (2012) ST Depression in Preeclampsia Women Receiving Oxytocin during Cesarean Section: A Randomized Controlled Trial. J Hypertens 1:108. doi:10.4172/2167-1095.1000108

\section{Clinical Trials Registration}

Clinical Trials.gov, NCT01530230 Eudura CTnr: 2004-004929-99.

\section{References}

1. Palmer CM, Norris MC, Giudici MC, Leighton BL, DeSimone CA (1990) Incidence of electrocardiographic changes during cesarean delivery under regional anesthesia. Anesth Analg 70: 36-43.

2. Jonsson M, Hanson U, Lidell C, Norden-Lindeberg S (2010) ST depression at caesarean section and the relation to oxytocin dose. A randomised controlled trial. BJOG 117: 76-83.

3. Svanstrom MC, Biber B, Hanes M, Johansson G, Naslund U, et al. (2008) Signs of myocardial ischaemia after injection of oxytocin: a randomized doubleblind comparison of oxytocin and methylergometrine during Caesarean section. $\mathrm{Br} J$ Anaesth 100: 683-689.

4. Langesaeter E, Rosseland LA, Stubhaug A (2006) Hemodynamic effects of oxytocin during cesarean delivery. Int J Gynaecol Obstet 95: 46-47.

5. Thomas JS, Koh SH, Cooper GM (2007) Haemodynamic effects of oxytocin given as i.v. bolus or infusion on women undergoing Caesarean section. $\mathrm{Br} \mathrm{J}$ Anaesth 98: 116-119.

6. Dyer RA, Piercy JL, Reed AR, Lombard CJ, Schoeman LK, et al. (2008) Hemodynamic changes associated with spinal anesthesia for cesarean delivery in severe preeclampsia. Anesthesiology 108: 802-811.

7. Langesaeter E, Rosseland LA, Stubhaug A (2011) Haemodynamic effects of oxytocin in women with severe preeclampsia. Int J Obstet Anesth 20: 26-29.

8. Prendiville WJ, Elbourne D, McDonald S (2000) Active versus expectant management in the third stage of labour. Cochrane Database SystRev 3: CD000007.
9. Hoffman $\mathrm{Jl}$ (1978) Determinants and prediction of transmural myocardial perfusion. Circulation 58: 381-391.

10. Sethna DH, Moffitt EA (1986) An appreciation of the coronary circulation. Anesth Analg 65: 294-305.

11. Terrone DA, Isler CM, May WL, Magann EF, Norman PF, et al. (2000) Cardiopulmonary morbidity as a complication of severe preeclampsia HELLP syndrome. J Perinatol 20: 78-81.

12. Munn MB, Owen J, Vincent R, Wakefield M, Chestnut $\mathrm{DH}$, et al. (2001) Comparison of two oxytocin regimens to prevent uterine atony at cesarean delivery: a randomized controlled trial. Obstet Gynecol 98: 386-390.

13. Lokugamage AU, Paine M, Bassaw-Balroop K, Sullivan KR, Refaey $H E$ et al. (2001) Active management of the third stage at caesarean section: a randomised controlled trial of misoprostol versus syntocinon. Aust N Z J Obstet Gynaecol 41: 411-414.

14. Bolton TJ, Randall K, Yentis SM (2003) Effect of the Confidential Enquiries into Maternal Deaths on the use of Syntocinon at Caesarean section in the UK. Anaesthesia 58: 277-279.

15. Tamhane P, O'Sullivan G, Reynolds F (2006) Oxytocin in parturients with cardiac disease. Int J Obstet Anesth 15: 332-333.

16. Aya AG, Mangin R, Vialles N, Ferrer JM, Robert C, et al. (2003) Patients with severe preeclampsia experience less hypotension during spinal anesthesia for elective cesarean delivery than healthy parturients: a prospective cohor comparison. Anesth Analg 97: 867-872.

17. Vedernikov Y, Saade GR, Garfield RE (1999) Vascular reactivity in preeclampsia. Semin Perinatol 23: 34-44. 